\title{
City development and population change in Iran: A case study of Sari
}

\author{
Ali Zangi Abadi ${ }^{{ }^{*}}$, Rostam Ali Pakdaman Koleti ${ }^{\mathrm{b}}$ and Mehdi Nasiri Khalili ${ }^{\mathrm{c}}$
}

${ }^{a}$ Associate Professor of Geography and Urban Planning, University of Isfahan, Iran

${ }^{b} \mathrm{PhD}$ Candidate of Urban Planning, Najaf Abad Branch, Islamic Azad University, Najaf Abad, Iran

${ }^{c}$ PhD Candidate of Geography and Urban Planning, Semnan Branch, Islamic Azad University, Semnan, Iran

\begin{tabular}{l}
\hline C H R O N I C L E \\
\hline Article history: \\
Received October 28, 2014 \\
Received in revised format 15 \\
January 2015 \\
Accepted 27 January 2015 \\
Available online \\
January 28 2015 \\
\hline Keywords: \\
City planning \\
Sari \\
Urban planning
\end{tabular}

\begin{abstract}
A B S T R A C T
This paper presents an empirical investigation on urban planning and development of a region located between Galugah to Noor in province of Sari located in north region of Iran. The study uses structural-functional approach as a strategic method for organizing space, at different levels and scales. To examine the descriptive analysis of demographic, social and physical environmental variables are studied. The validity of the models are accomplished using various techniques such as the Shannon entropy, Holdern, standardized scores, Williamson, HDI, and Spearman correlation coefficients. The results indicate that there was a weak correlation between HDI index and population of different regions. The study presents some useful comments and suggestions for development of the city.
\end{abstract}

\section{Introduction}

During the past few years, there have been tremendous efforts on city development in different regions of Iran (Kanôb, 1978; Parnell \& Robinson, 2006; Hedayati et al., 2011). Some people believe in development of cities, one must consider different criteria to reach sustainable development (Davidoff, 1965). Kenworthy (2006) named ten key transport and planning dimensions for sustainable city development and mentioned that a developed city must meet all these criteria. Liu et al. (2009) believe it is important to reach a low carbon industry to reach sustainable development. Others believe government must intervene for any city development by setting appropriate rules and regulations (Tian \& Ma, 2009). Lotfi et al. (2009) provided an analysis of urban land development using multi-criteria decision model and geographical information system in a case study of Babolsar City, located in North part of Iran.

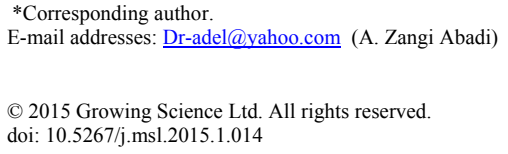




\section{The proposed study}

This paper presents an empirical investigation on urban planning and development of a region located between Galugah to Noor in province of Sari located in north region of Iran. The study uses structuralfunctional approach as a strategic method for organizing space, at different levels and scales. The city of Sari is the provincial capital of Mazandaran, Iran and, for a short period of time, former capital of Iran, located in the north part of Iran, between the northern slopes of the Alborz Mountains and southern coast of the Caspian Sea. The city is the largest and the most populous city of Mazandaran. Fig. 1 shows geographical position of the city in north part of Iran.

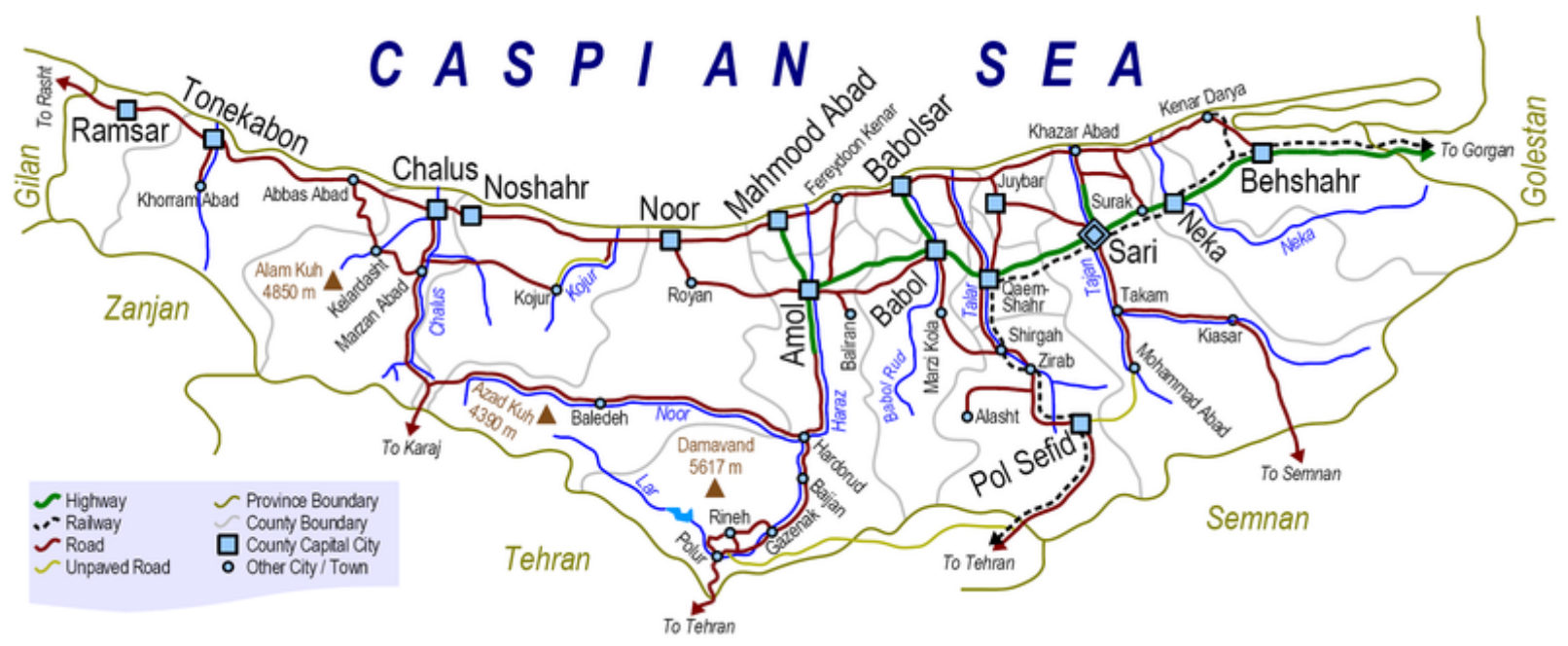

Fig. 1. The city of Sari in province of Mazandran

Sari's geographical coordinates are $36^{\circ} 34^{\prime} 4^{\prime \prime}$ North, 53 $3^{\circ}$ ' 31" East. The economy of the city is mainly based on food production such as milled rice, dairy products, canned meat, cookies, etc. Sari is the host of a major citrus fruits especially orange, tangerine and lemon producer. Oil seeds such as soybean and rape are cultivated around villages for producing of vegetable ghee and cooking oil. Paper, wood, fabrics and construction material are other sources of income for the economy of the city. According to recent survey accomplished in 2011, there were 296,700 people residing in city of Sari. The population of the city of Sari (in the law range) from 1957 to 2012, was increased approximately 12times and form 26 thousand person in 1957 reached to 296 thousand people in 2012. Table 1 shows index of population of sari city from 1976 to 2012.

\section{Table 1}

Demographic characteristics of sari city over the period 1976-2012

\begin{tabular}{lccccc}
\hline Demographic indicators & $(1976-77)$ & $(1986-87)$ & $(1996-97)$ & $(2006-07)$ & $(2011-12)$ \\
\hline Population (people) & 70753 & 141020 & 195882 & 261293 & 296417 \\
Number of households & 15527 & 29830 & 44280 & 71564 & 90798 \\
The average household size & 4.6 & 4.7 & 4.4 & 3.7 & 3.26 \\
\hline Average annual growth (period) & - & 7.1 & 3.3 & & 2.5 \\
\hline
\end{tabular}

There are three regions in the city including costal region, production and natural resources. Also, the natural growth rate of Sari population after reduction year of before revolution increased to 3.5 percent. However, with reduction fertility and because of reduction rate bearing of more than 40 per thousand to fewer than 20 per thousand in period 1992-1997 and 15.1 per thousand during the 2001-2006, rate of practice growth of peace population from around the 12 per thousand went down to 5 per thousand. The net result is not fitted with fertility reduction level of city of Sari (Nasiri Khalili et al., 2015). The main reason is due to non- existence of proportion between this fertility level and the rate of bearing that is because of young population, which reflects at the top amount of the natural growth. With this 
fertility level of Sari city women could be anticipated that the rate of practice growth of peace in this city could lead to negative numbers. Overviews indicate that during the period 2001-2006, of approximately 1.9 annual growth rate from 2.9 percent of sari city population was from exchange population of this city with the other settlements of human province or out of province. In addition, Sari city had a structure with one central area and several weak core with patterns of relationship between the radius - ring structure (with being insufficient at ring form) that on its basis a network of centers and subjects colleague and urban supplement at space diverse were created, and it has made this city strongly ready for missions within or outside the city (Nasiri Khalili et al,, 2015). The long term urban planning deigned by the government has divided to 4 main regions and 11 sub-region.

\section{The proposed study}

\subsection{Shannon entropy}

Entropy is the concept of physics, social sciences and information theory and it states the provided uncertainty level of the expected data content of a message. In other words, entropy in information theory is a criterion for expressed uncertainty level through a discrete probability distribution as if the uncertainty were more discrete distribution than lower frequency distribution (Hashemzadeh et al., 2014). The Shannon Entropy $(\mathrm{H})$ is calculated as follows,

$$
H=-\sum_{i=1}^{m}\left[P_{i} \cdot \operatorname{Ln} P_{i}\right]
$$

where $P_{i}$ represents the ratio of the area of constructed facility $i$ compared with all constructed areas. The implementation of the Shannon Entropy on the city of Sari for two years of 2000 and 2014 yields 3.157 and 2.230, respectively. This means that physical development was sporadic and noncondensing.

\subsection{Heldern entropy}

Heldern is one of the primary techniques for determining uneven urban growth. In this method, we determine the amount of city growth according to population growth and the amount of uneven urban growth. This model first was implemented to calculate the ratio population to any other source by Heldern in 1991. According to Beck et al. (2003), the method first calculates per capita GDP as follows,

$$
\mathrm{a}=\mathrm{A} / \mathrm{P},
$$

where per capita GDP (a) represents the product of the area (A) divided by Population (P). Next, we calculate Heldern as follows,

$$
\operatorname{Ln}(\mathrm{P} / \mathrm{w})+\ln (\mathrm{e} / \mathrm{r})=\ln (\mathrm{y} / \mathrm{s})
$$

where $P$ represents of end Period, $W$ represents of start period, $E$ is impure capitation of end period, $R$ is impure capitation of start period, $Y$ is city extent at end period and, $S$ is the city extent at start period. The implementation of Heldern indicates that nearly $82 \%$ of the growth of the city over a 50 year period was associated with population and only $18 \%$ was related to land growth.

\subsection{Williamson method}

In this section, we consider the effect of expansion of the distribution pattern of land uses based on Williamson method. In this method, one of the important city development factors is associated with density, distribution of administrative units, commercial and allocation of land for urban services. The Williamson formula (CV) is calculated as follows, 


$$
C V=\frac{\frac{1}{m} \sqrt{\sum_{i=1}^{m}\left(x_{i}-\bar{x}\right)^{2}}}{\frac{1}{m} \sum_{i=1}^{m} x_{i}}
$$

where $x_{i}$ represents the attribute $i, m$, represents the number of regions and $\bar{x}$ represents the average of attributes.

\subsection{Standard method}

In this method, we measure deviation from different criteria as follows,

$$
\begin{aligned}
& S S_{i j}=\frac{x_{i j}-\bar{x}}{\sigma i}, \\
& S S_{j}=\frac{1}{m} \sum S S_{i j} .
\end{aligned}
$$

The implementation of Eq. (5) and Eq. (6) has indicated that there were 4 sub-region in relatively good conditions and 5 sub-region in completely bad conditions in terms of city development.

\subsection{Human development index}

Human development index (HDI) (Havighurst, 1953) is another method for studying the development ratios of the city. Human Development Index (HDI) is a kind of statistics based on life expectancy, education, and income indices implemented to rank countries into four tiers of human development. The index is calculated as follows,

$$
H D I=\frac{x-\min (x)}{\max (x)-\min (x)}
$$

where $x$ is an attribute, which is compared with min and max. Table 2 demonstrates the index for 4

\begin{tabular}{|c|c|c|c|c|c|c|c|c|c|c|c|c|}
\hline 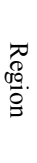 & 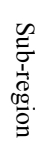 & 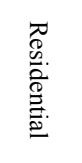 & 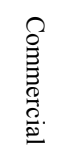 & 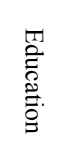 & 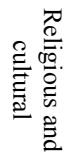 & 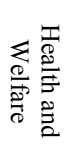 & $\frac{\stackrel{\vec{D}}{\overrightarrow{0}}}{\stackrel{0}{\overrightarrow{0}}}$ & 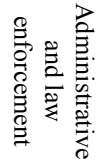 & 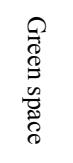 & $\mathrm{xj}$ & HDI & Status \\
\hline \multirow{4}{*}{1} & 1 & 0.076 & 0 & 0.106 & 0 & 0.995 & 0 & 0.266 & 0.038 & 0.18512 & 0.81487 & Good \\
\hline & 2 & 0.386 & 0.593 & 0.548 & 0.417 & 0 & 1 & 0.151 & 0 & 0.38687 & 0.61312 & Average \\
\hline & 3 & 1 & 0.68 & 1 & 0.548 & 0.434 & 0.21 & 0.346 & 0.008 & 0.52825 & 0.47175 & $\mathrm{Bad}$ \\
\hline & 4 & 0.497 & 0.411 & 0.603 & 0.71 & 0.065 & 0.599 & 1 & 0.114 & 0.49987 & 0.50012 & Average \\
\hline \multirow{4}{*}{2} & 1 & 0.837 & 0.456 & 0.203 & 0.947 & 0.24 & 0.044 & 0.262 & 0 & 0.37362 & 0.62637 & Average \\
\hline & 2 & 0.311 & 0.116 & 0.245 & 1 & 0.047 & 0.159 & 0.052 & 1 & 0.36625 & 0.63375 & Average \\
\hline & 3 & 0.536 & 0.227 & 0.528 & 0.26 & 0.572 & 0.113 & 0.414 & 0.028 & 0.33475 & 0.66525 & Average \\
\hline & 4 & 0 & 0.002 & 0 & 0.014 & 0.016 & 0.003 & 0.186 & 0 & 0.02762 & 0.97237 & Good \\
\hline \multirow{2}{*}{3} & 1 & 0.91 & 0.437 & 0.151 & 0.581 & 0.067 & 0.026 & 0.007 & 0.406 & 0.32312 & 0.67687 & Average \\
\hline & 2 & 0.685 & 0.238 & 0.175 & 0.479 & 0.68 & 0.266 & 0 & 0.252 & 0.34687 & 0.65312 & Average \\
\hline 4 & 1 & 0.015 & 1 & 0.333 & 0.967 & 0.376 & 0.98 & 0.149 & 0.45 & 0.53375 & 0.46625 & $\mathrm{Bad}$ \\
\hline
\end{tabular}
main regions of the city.

Table 2

The results of HDI index 
As we can observe from the results of Table 2, HDI index is within desirable level in two out of 11 subregion and it is undesirable in two sub-region. In most other regions, HDI index is on average level. We have also performed Spearman ranking method to see whether there is any relationship between HDI index and population. Table 3 demonstrates the results of our survey.

Table 3

The summary of Spearman correlation test between HDI index and population

\begin{tabular}{|c|c|c|c|c|c|c|}
\hline Region & Sub-region & Population & Rank of population & HDI rank & $\mathrm{d}$ & $d^{2}$ \\
\hline \multirow{4}{*}{1} & 1 & 14740 & 9 & 2 & 7 & 49 \\
\hline & 2 & 27904 & 7 & 8 & -1 & 1 \\
\hline & 3 & 42043 & 2 & 10 & -8 & 64 \\
\hline & 4 & 29310 & 6 & 1 & 5 & 25 \\
\hline \multirow{4}{*}{2} & 1 & 42014 & 3 & 7 & -4 & 16 \\
\hline & 2 & 18754 & 8 & 6 & 4 & 16 \\
\hline & 3 & 35714 & 5 & 4 & 1 & 1 \\
\hline & 4 & 13407 & 11 & 9 & 2 & 4 \\
\hline \multirow{2}{*}{3} & 1 & 47250 & 1 & 3 & -2 & 4 \\
\hline & 2 & 38901 & 4 & 5 & -1 & 1 \\
\hline 4 & 1 & 13753 & 10 & 11 & -1 & 1 \\
\hline
\end{tabular}

The Spearman correlation ratio is calculated as follows,

$$
r_{s}=1-\frac{6 \sum_{i=1}^{k} d_{i}^{2}}{n\left(n^{2}-1\right)} .
$$

The implementation of Spearman correlation ratio using the information of Table 2 yields $r_{s}=0.18$, which means there is a weak correlation between HDI index and population in different regions.

\section{Conclusion}

In this paper, we have presented an empirical investigation to study urban planning development in city of Sari, Iran. The study has determined that the city was under inappropriate development in terms of population and there was not a good correlation between HDI index and population density of the city. There are some evidences to believe that the city structure must be changed from industrial identity to service industry. In development and expansion of the city, variety of factors, particularly environmental geomorphologic phenomena must be studied in various aspects. By increasing the density per unit area, more services must be provided to citizens. This could happen by preventing city population to grow in regional areas. Multi-story housing must be considered to prevent further rapid growth and expansion of landscape level planning for deficiency in services. This could happen by filling empty spaces inside the city, transferring illegal and incompatible land uses (industrial use) out of town, implementation of rehabilitation and reconstruction of the historic fabric of the city and increasing residential density in the old region through accelerating construction in this region.

\section{Acknowledgment}

The authors would like to thank the anonymous referees for constructive comments on earlier version of this paper.

\section{References}

Beck, R. H., Kolankiewicz, L. J., \& Camarota, S. A. (2003). Outsmarting smart growth: Population growth, immigration, and the problem of sprawl. Center for Immigration Studies. 
Davidoff, P. (1965). Advocacy and pluralism in planning. Journal of the American Institute of Planners, 31(4), 331-338.

Hashemzadeh, G.R., Khoshtarkib, M., \& Hajizadeh, S. (2014). Identification and weighting factors influencing the establishment of a single minute exchange of dies in plastic injection industry using VIKOR and Shannon Entropy. Decision Science Letters, 4, 977-984.

Havighurst, R. J. (1953). Human development and education.

Hedayati, M. T., Mayahi, S., Movahedi, M., \& Shokohi, T. (2011). Study on fungal flora of tap water as a potential reservoir of fungi in hospitals in Sari city, Iran. Journal de Mycologie Médicale/Journal of Medical Mycology, 21(1), 10-14.

Kanôb, H. (1978). City development and occupational change in Iran: A case study of Hamadan. The Developing Economies, 16(3), 298-328.

Kenworthy, J. R. (2006). The eco-city: ten key transport and planning dimensions for sustainable city development. Environment and urbanization,18(1), 67-85.

Liu, Z. L., Dai, Y. X., Dong, C. G., \& Qi, Y. (2009). Low-carbon city: Concepts, international practice and implications for China. Urban Studies, 16(6), 1-7.

Lotfi, S., Habibi, K., \& Koohsari, M. J. (2009). An analysis of urban land development using multicriteria decision model and geographical information system (a case study of Babolsar City). American Journal of Environmental Sciences, 5(1), 87.

Nasiri Khalili, M.M., Abya, H., Ebrahimi, M., Tavallaee, S., Soleymani, M., \& Kamanroudi, M. (2015). Analysis of physical expansion and sprawl growth factors of Sari city using Shannon and Heldern entropy models. Management Science Letters, 5(1), 189-198.

Parnell, S., \& Robinson, J. (2006). Development and urban policy: Johannesburg's city development strategy. Urban Studies, 43(2), 337-355.

Tian, L., \& Ma, W. (2009). Government intervention in city development of China: A tool of land supply. Land Use Policy, 26(3), 599-609. 